\title{
Performed Clinical Result Biomarker Indicator
}

National Cancer Institute

\section{Source}

National Cancer Institute. Performed Clinical Result Biomarker Indicator. NCI Thesaurus.

Code C93909.

Specifies whether a result is considered a biomarker. 